\title{
Fetal haemoglobin levels in adult Type 1 (insulin-dependent) diabetic patients
}

\author{
P.Diem $^{1}$, P.Mullis ${ }^{2}$, A.Hirt ${ }^{2}$, J.J.Schuler ${ }^{3}$, W.Bürgi ${ }^{4}$, K. A.Zuppinger ${ }^{2}$ and A. Teuscher $^{1}$ \\ ${ }^{1}$ Diabetes Section, Division of Endocrinology and Diabetes, Department of Medicine, and ${ }^{2}$ Department of Paediatrics, University of Bern, \\ Inselspital, Bern; ${ }^{3}$ Enzyme Laboratory, Dr. H. Weber Inc., St. Gallen; ${ }^{4}$ Central Laboratory, Kantonsspital, Aarau, Switzerland
}

\begin{abstract}
Summary. Glycated haemoglobin levels $\left(\mathrm{HbA}_{1}\right.$ and $\left.\mathrm{HbA}_{1 \mathrm{c}}\right)$ are established parameters of long-term glycaemic control in diabetic patients. Depending on the method used, fetal haemoglobin interferes with the assays for glycated haemoglobin. If present in high amounts, fetal haemoglobin may lead to overestimation of glycated haemoglobin levels, and therefore, of average blood glucose concentration in diabetic patients. Glycated $\left(\mathrm{HbA}_{1 \mathrm{c}}\right)$ and fetal haemoglobin levels were measured by high pressure liquid chromatography in 60 (30 female) adult Type 1 (insulin-dependent) diabetic patients of Swiss descent, and were compared with levels obtained from 60 normal, non-diabetic control subjects matched for age and sex. Fetal haemoglobin levels were significantly higher in the diabetic patients $(0.6 \pm 0.1 \%$, mean \pm SEM; range: $0-3.6 \%$ ) than in the control subjects $(0.4 \pm 0.1 \%, p<0.001)$. Elevated fetal haemoglobin levels $(\geq 0.6 \%)$ were found in 23 of 60 diabetic patients $(38 \%)$
\end{abstract}

Glycated haemoglobin levels $\left(\mathrm{HbA}_{1}\right.$ and $\left.\mathrm{HbA}_{1 \mathrm{c}}\right)$ are established parameters of long-term glycaemic control [1-4]. Fetal haemoglobin (HbF) co-migrates with $\mathrm{HbA}_{1 \mathrm{c}}$, when glycated haemoglobin is determined using ion-exchange based microcolumns or electrophoretic methods. If present in high amounts, $\mathrm{HbF}$ may lead to overestimation of glycated haemoglobin levels, and consequently to overestimation of average blood glucose concentration [5]. In humans, $\mathrm{HbF}$ represents the major fetal haemoglobin the level of which begins to decrease late in gestation, and further declines rapidly in the neonatal period. By 6 months of age, $\mathrm{HbF}$ accounts for less than $5 \%$ of the total haemoglobin. In adults $\mathrm{HbF}$ levels are usually below $0.5 \%$. However, elevated $\mathrm{HbF}$ levels have been reported in diabetic children with the elevation appearing to decline with age [6].

Presented in part at the 59th Annual Meeting of the Swiss Society of Internal Medicine, Lugano, 1991 and at the 14th International Diabetes Federation Congress, Washington, 1991 compared to 9 of 60 control subjects $\left(15 \% ; \chi^{2}=8.35\right.$, $p<0.01$ ). In addition, fetal haemoglobin levels in diabetic patients are weakly correlated with glycated haemoglobin $\left(\mathrm{HbA}_{1 \mathrm{c}}\right)(r=0.38, p<0.01)$. Fetal haemoglobin results were confirmed with the alkali denaturation procedure, and by immunocytochemistry using a polyclonal rabbit anti-fetal haemoglobin antibody. A significant proportion of adult patients with Type 1 diabetes has elevated fetal haemoglobin levels. In certain patients this may lead to a substantial overestimation of glycated haemoglobin levels, and consequently of estimated, average blood glucose levels. The reason for this increased prevalence of elevated fetal haemoglobin remains unclear, but it may be associated with poor glycaemic control.

Key words: Type 1 (insulin-dependent) diabetes mellitus, glycaemic control, $\mathrm{HbA}_{1 \mathrm{cc}}$, fetal haemoglobin.

\section{Subjects and methods}

\section{Subjects}

Sixty adult Type 1 diabetic patients of Swiss descent, and 60 normal, non-diabetic control subjects of Swiss descent matched for age and sex (Table 1) were studied. Control subjects were chosen from among hospital staff. Since $\mathrm{HbF}$ continues to decline throughout adult life [7], particular care was taken to match patients and control subjects for age. Pairs of diabetic and control subjects were formed with less than 24 months age difference within pairs. Mean age was $33 \pm 1$ years (mean \pm SEM) in both groups (range 18-59 years in diabetic patients and $19-59$ years in control subjects). None of the diabetic patients were anaemic or had nephropathy with increased creatinine levels or macroproteinuria, as these are conditions that might affect erythrocyte survival time and, therefore, glycated haemoglobin levels. 
Table 1. Clinical characteristics of adult Type 1 diabetic patients and normal, non-diabetic control subjects

\begin{tabular}{lll}
\hline & Type 1 diabetic patients & Control subjects \\
\hline$n$ & 60 & 60 \\
Age (years) & $33 \pm 1$ & $33 \pm 1$ \\
Sex (female/male) & $30 / 30$ & $30 / 30$ \\
$\mathrm{HbA}_{1 \mathrm{c}}(\%)$ & $8.4 \pm 0.2^{\mathrm{a}}$ & $5.1 \pm 0.1$ \\
\hline
\end{tabular}

${ }^{a} p<0.001$ vs control subjects.

Values shown are mean \pm SEM

Table 2. Prevalence of increased fetal haemoglobin ( $\mathrm{HbF}$ ) levels in adult Type 1 diabetic patients and in normal control subjects matched for age and sex

\begin{tabular}{lll}
\hline $\mathrm{HbF}$ & Type 1 diabetic patients & Control subjects \\
\hline$\leq 0.5 \%$ & 37 & 51 \\
$\geq 0.6 \%$ & 23 & 9 \\
\hline
\end{tabular}

Type 1 diabetic patients vs control subjects: $\chi^{2}=8.35, p<0.01$

\section{Analytical methods}

$\mathrm{HbA}_{1 \mathrm{c}}$ and $\mathrm{HbF}$ were determined by HPLC using a Diamat analyser (Bio-Rad, Glattbrugg, Switzerland). This automated device measures simultaneously (stable) $\mathrm{HbA}_{1 \mathrm{c}}$ and $\mathrm{HbF}$. After pre-incubation with a haemolysing reagent containing a borate buffer allowing the simultaneous elimination of labile $\mathrm{HbA}_{1 c}$, the haemolysate is applied to cation-exchange analytical columns maintained at $23^{\circ} \mathrm{C}$. The fractions are separated by step-gradient elution using phosphate buffers of increasing ionic strength and detected by a dual wavelength photometer at wave lengths of $415 \mathrm{~nm}$ and $690 \mathrm{~nm}$. The data are then processed by a built-in data module to identify and calculate the areas under the peaks. With this method, the elution of the various zones is highly reproducible and the haemoglobin peaks are sharp. The HbF intraassay coefficient of variation (CV) was $4.5 \%$ at $0.7 \% \mathrm{HbF}$ and the corresponding interassay $\mathrm{CV}$ was $9.8 \%$, for $\mathrm{HbA}_{1 \mathrm{c}}$, CVs were below $2 \%$. In a subset of 10 diabetic patients with $\mathrm{HbF}$ levels of $0.5 \%$ or higher, $\mathrm{HbF}$ was also determined using the alkali denaturation procedure [8]. In three patients blood smears which had been air dried, were fixed in methanol: acetone (1:6) for $10 \mathrm{~min}$ at room temperature. The slides were then stained using a polyclonal rabbit anti-human $\mathrm{HbF}$-antibody (Calbiochem, Läufelfingen, Switzerland), followed by an alkaline phosphatase conjugated porcine anti-rabbit IgG-antibody (Dakopatts, Instrumenten-Gesellschaft, Zürich, Switzerland). The colour reaction was performed with a substrate solution containing Naphthol AS-BI-phosphate and Fast Red TR (Sigma Chemicals Inc., St. Louis, Mo., USA). Slides were then evaluated by light microscopy for the percentage of erythrocytes containing HbF stained red by immunocytochemistry.

\section{Statistical analysis}

Data are presented as mean \pm SEM. Statistics for inter-group comparisons were performed by non-parametric analysis of variance (Kruskal-Wallis). Discrete variables were compared by chi-square $\left(\chi^{2}\right)$ analysis. Least-squares linear regression analysis, and Pearson correlation coefficients were used to assess bivariate interdependency. A $p$ value of less than 0.05 was considered statistically significant.

\section{Results}

In the present series, we found $\mathrm{HbF}$ levels that were significantly higher in adult Type 1 diabetic patients $(0.6 \pm 0.1 \%$, mean \pm SEM $)$ than in the control subjects matched for age and sex $(0.4 \pm 0.1 \%, p>0.001)$. In individual Type 1 diabetic patients, $\mathrm{HbF}$ ranged from $0-3.6 \%$. HbF levels $0.6 \%$ or more (> 80th percentile of normal control subjects) were found in 23 (15 female and 8 male) of the 60 Type 1 diabetic patients compared to 9 of the 60 control subjects $\left(\chi^{2}=8.35, p<0.01\right.$; Table 2).

To validate the HPLC findings, results obtained by HPLC were compared with $\mathrm{HbF}$ levels assayed by the alkali denaturation procedure in a subgroup of 10 Type 1 diabetic patients. As shown in Figure 1, there was an excellent correlation between $\mathrm{HbF}$ measured by the two techniques $(r=0.97, p<0.001)$. Even if the patient with the highest $\mathrm{HbF}$ levels is excluded from the statistical analysis, the correlation remains highly significant $(r=0.84, p<0.01)$. In addition, using a polyclonal, rabbit anti-HbF-antibody, intracellular $\mathrm{HbF}$ was confirmed in three patients. Most interestingly, the smears showed that $\mathrm{HbF}$ is not present in all erythrocytes, but rather confined to a subset of cells with $27 \%, 21 \%$, and $17 \%$, respectively of erythrocytes containing $\mathrm{HbF}$ stained by immunocytochemistry (Fig.2). Figure 3 shows that $\mathrm{HbF}$ levels in

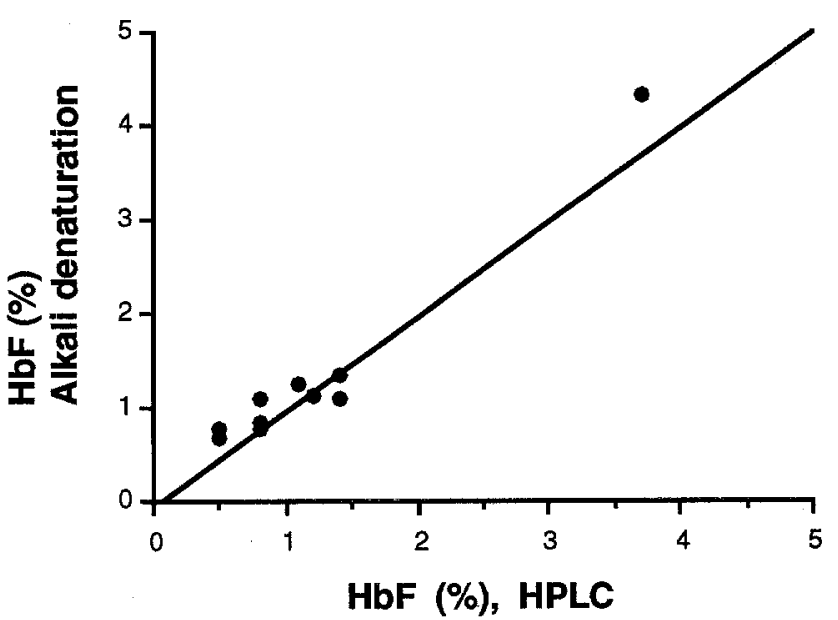

Fig. 1. Correlation between fetal haemoglobin (Hbf) measured by HPLC and HbF measured by alkali denaturation in 10 adult Type 1 diabetic patients with $\mathrm{HbF}$ levels of $0.5 \%$ or more $(r=0.97)$

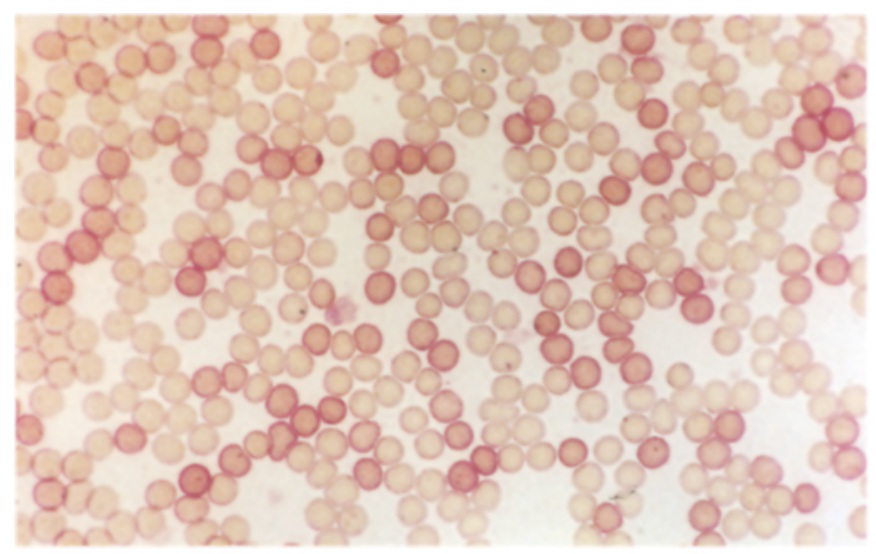

Fig. 2. Fetal haemoglobin (HbF) shown by immunocytochemistry using a polyclonal, rabbit anti-HbF-antibody. HbF-containing cells stain darker. The smear is taken from an adult Type 1 diabetic patient with $\mathrm{HbF}$ levels of $3.6 \%$ 


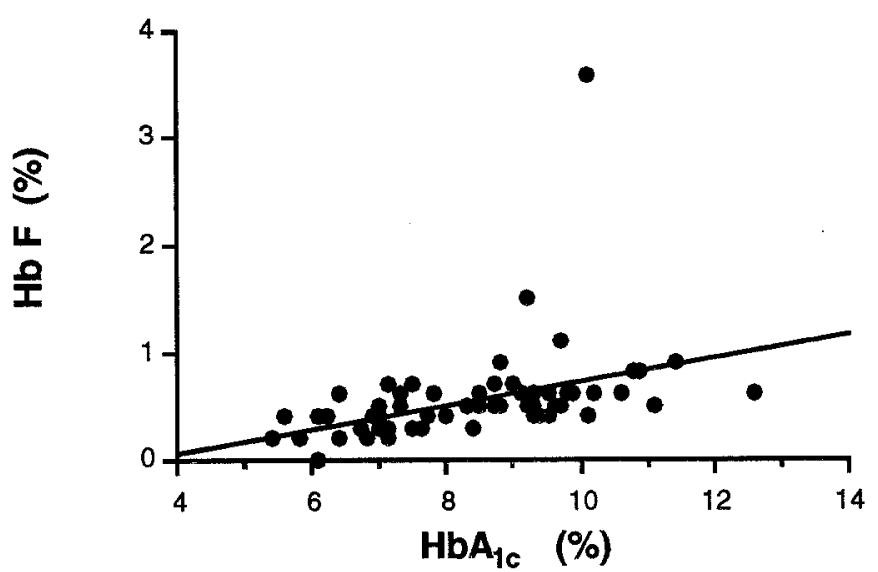

Fig.3. Correlation between fetal haemoglobin (HbF) measured by HPLC and $\mathrm{HbA}_{1 \mathrm{c}}$ measured by HPLC in 60 adult Type 1 diabetic patients $(r=0.38)$

Type 1 diabetic patients are related to the degree of metabolic control: there is in fact a weak but significant correlation between $\mathrm{HbA}_{1 \mathrm{c}}$ and $\mathrm{HbF}$ levels with $r=0.38$ $(p<0.01)$. If the outlier with an $\mathrm{HbF}$ level of $3.6 \%$ were excluded from the analysis, the correlation coefficient would be $r=0.52(p<0.0001)$. In contrast, there were no significant correlations of HbF levels with age $(r=0.17)$ or diabetes duration $(r=0.01)$.

\section{Discussion}

We have found a small but clinically important elevation of $\mathrm{HbF}$ levels in adult Type 1 diabetic patients. This finding is in agreement with a previous report showing increased $\mathrm{HbF}$ levels in Type 1 diabetic children and adolescents [6]. The elevated HbF levels in diabetic patients are not a mere artefact of the HPLC method used, since the results could be confirmed by immunocytochemistry using a polyclonal rabbit anti-HbF-antibody, and with the alkali denaturation procedure. In individual patients, elevated $\mathrm{HbF}$ levels may have a considerable impact on the interpretation of glycated haemoglobin levels, and thus, on the management of the diabetic patient.

The elevation of $\mathrm{HbF}$ in Type 1 diabetic patients is difficult to explain. In contrast to $\mathrm{HbA}$ which is composed of two $\alpha$-chains and two $\beta$-chains, $\mathrm{HbF}$ is composed of two $\alpha$-chains and two $\gamma$-chains. In adults, the persisting amount of $\mathrm{HbF}$ is confined to a small erythrocyte population called F-cells. The mechanisms regulating $\gamma$-chain gene expression are poorly understood. Elevated levels of $\mathrm{HbF}$ have been reported in patients with haematological malignancies [9], $\beta$-thalassaemias [10] or sickle-cell disease [11]. Based on past medical history, normal haemoglobin concentration and normal blood smears, such conditions can be excluded in the patients included in this study. Interestingly, butyrate, and some butyric acid analogues have been shown to increase $\mathrm{HbF}$ levels $[12,13]$ and $\gamma$-chain gene expression $[14,15]$. The effect of butyrates on $\mathrm{HbF}$ levels has been ascribed to localized modifica- tions of the DNA, e.g. following therapy with butyric acid analogues, altered methylation of DNA has been proposed as a possible mechanism [16]. Based on these studies, treatment with butyrates has been proposed as a possible therapy of $\beta$-globin diseases [17]. The correlation between $\mathrm{HbF}$ and $\mathrm{Hb} \mathrm{A}_{1 \mathrm{c}}$ found in this study, together with the known delay in the fetal globin switch in infants of diabetic mothers $[17,18]$ suggests that metabolic derangements associated with Type 1 diabetes are able to activate $\mathrm{HbF}$ synthesis. Based on the preliminary finding that $\mathrm{HbF}$ levels are not elevated in Type 2 (non-insulin-dependent) diabetic patients [19], and the fact that certain butyrates enhance $\gamma$-chain gene expression in vitro and in vivo, one may speculate that in Type 1 diabetic patients, one or several factors associated with poor metabolic control (e.g. episodes of increased ketogenesis with elevated levels of $\beta$-hydroxy-butyrate) affect the switch from $\gamma$-chain to $\beta$-chain expression, and lead to increased $\gamma$-chain gene expression.

In conclusion, $\mathrm{HbF}$ levels are increased in some adult Type 1 diabetic patients. If glycated haemoglobin is measured by ion-exchange based microcolumns or by electrophoretic techniques $\mathrm{HbA}_{1 \mathrm{c}}$ (and also total $\mathrm{HbA}_{1}$ ), levels may be falsely elevated leading to an overestimation of average blood glucose levels. Interference of $\mathrm{HbF}$ with $\mathrm{HbA}_{1 \mathrm{c}}$ determinations can be avoided by using more specific procedures (HPLC, affinity chromatography, thiobarbituric acid, or radioimmunoassay).

Acknowledgements. We thank Ms. M. Walther and Ms. I.Schmid for technical assistance and Ms. S. Bürki for help with the illustrations.

\section{References}

1. Anonymous (1980) Haemoglobin $A_{1}$ and diabetes: a reappraisal. Br Med J 281: 1304-1305 (Editorial)

2. Goldstein DE, Parker KM, England JD et al. (1982) Clinical applications of glycosylated hemoglobin measurements. Diabetes 31 [Suppl 3]: 70-78

3. Svendsen PA, Lauritzen T, Søegaard U, Nerup J (1982) Glycosylated haemoglobin and steady-state mean blood glucose concentration in type 1 (insulin-dependent) diabetes. Diabetologia 23: 403-405

4. Nathan DM, Singer DE, Hurxthal K, Goodson JD (1984) The clinical information value of the glycosylated hemoglobin assay. N Engl J Med 310: 341-346

5. Yatscoff RW, Tevaarwerk JM, Clarson CL, Warnock LM (1983) Interference of fetal hemoglobin and labile glycosylated hemoglobin with measurements of glycosylated hemoglobin. Clin Chem 29: 543-545

6. Mullis P, Schuler J, Zuppinger K (1989) Increased prevalence of fetal haemoglobin in type 1 (insulin-dependent) diabetes mellitus. Diabetologia 32: 227-230

7. Wood WG (1989) HbF production in adult life. Progr Clin Biol Res 316: 251-267

8. Betke K, Marti HR, Schlicht I (1959) Estimation of small percentages of foetal haemoglobin. Nature 184: 1877-1878

9. Weatherall DJ, Clegg JB, Wood WG, Callender ST, Sheridan BL, Pritchard J (1975) Foetal erythropoiesis in human leukaemia. Nature 257: 710-712

10. Beaven GH, Ellis MJ, White JC (1961) Studies on human foetal haemoglobin. III. The hereditary haemoglobinopathies and thalassaemias. Br J Haematol 7: 159-186 
11. Perrine RP, Pembrey ME, John P, Perrine S, Shoup F (1978) Natural history of sickle cell anemia in Saudi Arabs. Ann Int Med 88: 1-6

12. Constantoulakis $P$, Knitter G, Stamatoyannopoulos G (1989) On the induction of fetal hemoglobin by butyrates: in vivo and in vitro studies with sodium butyrate and comparison of combination treatments with 5-AzaC and AraC. Blood 74: 1963-1971

13. Constantoulakis P, Knitter G, Stamatoyannopoulos G (1989) Butyrate stimulates $\mathrm{HbF}$ in adult baboons. Progr Clin Biol Res 316: 351-361

14. Perrine SP, Miller BA, Green MF et al. (1987) Butyric acid analogues augment $\gamma$-globin gene expression in neonatal progenitors. Biochem Biophys Res Commun 148: 694-700

15. Perrine SP, Miller BA, Faller DV et al. (1989) Sodium butyrate enhances fetal globin gene expression in erythroid progenitors of patients with $\mathrm{HbSS}$ and $\beta$ thalassemia. Blood 74: 454-459

16. Burns JL, Glauber GJ, Ginder DG (1988) Butyrate induces selective transcriptional activation of a hypomethylated embryonic globin gene in adult erythroid cells. Blood 72: 1536-1542
17. Perrine SP, Green MF, Faller DV (1985) Delay in the fetal globin switch in infants of diabetic mothers. N Engl J Med 312:334-338

18. Bard H, Prosmanne J (1985) Relative rates of fetal hemoglobin and adult hemoglobin in cord blood of infants of insulin-dependent mothers. Pediatrics 75: 1143-1147

19. Kilpatrick ES, Rumley A, Cunningham S, Small M, Dominiczak MH (1991) Abnormal foetal haemoglobin concentrations may be responsible for discrepancies in the assessment of diabetic control by electrophoretic methods for glycated haemoglobin measurements. Diabetic Med 8 [Suppl.1]:22 A (Abstract)

Received: 1 July 1992 and in revised form: 1 October 1992

Dr.P.Diem

Diabetesstation

Medizinische Universitätsklinik

Inselspital

$\mathrm{CH}-3010$ Bern

Switzerland 